\title{
Erratum zu: Rohland, Eleonora: Changes in the Air. Hurricanes in New Orleans from 1718 to the Present, 252 S., Berghahn, Oxford/New York 2018
}

\author{
Andreas Hübner
}

Online publiziert: 24. August 2021

(C) Der/die Autor(en) 2021

\section{Erratum zu:}

Neue Polit. Lit. 65, 307-310 2020

https://doi.org/10.1007/s42520-020-00237-y

Der Artikel „Rohland, Eleonora: Changes in the Air. Hurricanes in New Orleans from 1718 to the Present, 252 S., Berghahn, Oxford/New York 2018." von Andreas Hübner wurde ursprünglich Online First ohne „Open Access“ auf der Internetplattform des Verlags publiziert. Nach der Veröffentlichung in Bd. 65, Heft 2, pp. 307-310 hatten sich die Autoren für eine „Open Access“-Veröffentlichung entschieden. Das Urheberrecht des Artikels wurde deshalb in @ D Der/die Autor(en) 2020 geändert.

Funding Open Access funding enabled and organized by Projekt DEAL. Open Access

Open Access Dieser Artikel wird unter der Creative Commons Namensnennung 4.0 International Lizenz veröffentlicht, welche die Nutzung, Vervielfältigung, Bearbeitung, Verbreitung und Wiedergabe in jeglichem Medium und Format erlaubt, sofern Sie den/die ursprünglichen Autor(en) und die Quelle ordnungsgemäß nennen, einen Link zur Creative Commons Lizenz beifügen und angeben, ob Änderungen vorgenommen wurden.

Die in diesem Artikel enthaltenen Bilder und sonstiges Drittmaterial unterliegen ebenfalls der genannten Creative Commons Lizenz, sofern sich aus der Abbildungslegende nichts anderes ergibt. Sofern das betreffende Material nicht unter der genannten Creative Commons Lizenz steht und die betreffende Handlung nicht nach gesetzlichen Vorschriften erlaubt ist, ist für die oben aufgeführten Weiterverwendungen des Materials die Einwilligung des jeweiligen Rechteinhabers einzuholen.

Die Online-Version des Originalartikels ist unter https://doi.org/10.1007/s42520-020-00237-y zu finden.

Andreas Hübner $(\bowtie)$

Leuphana Universität Lüneburg, Lüneburg, Deutschland

E-Mail: andreas.huebner@leuphana.de 
Weitere Details zur Lizenz entnehmen Sie bitte der Lizenzinformation auf http://creativecommons.org/ licenses/by/4.0/deed.de. 